REVISTA PROYECCIONES N ${ }^{\circ} 10: 167-167$

Diciembre 1985 - ISSN 0716-0917

Jornada Matemáticas, Agosto 1985.

\title{
ESTRUCTURAS MATROIDALES Y OPTIMIZACIÓN
}

RAUL CORNEJO ROMERO*

\section{RESUMEN .}

Este trabajo consiste en presentar inicialmente el concepto de MATROIDE, lo que se hará a través de tres definiciones alternativas y equi valente, destacándose las dos primeras por su formulación teórica y la úl tima por su relación misma con la optimización combinatoria. Luego se ana lizan algunos casos particulares de matroides, para finalmente mostrar co mo un problema de optimización en una estructura no matroidal puede ser resuelto pensándolo como un problema de intersección de dos matroides.

* Departamento de Matemáticas, Universidad de Tarapacá, Arica. 